\section{Infantile Herpes Zoster after Intrauterine Exposure to Varicella}

\section{K. LEWKONIA, A. A. JACKSON}

British Medical fournal, 1973, 3, 149

It has now been firmly established by cultural (Weller, 1958), serological (Weller and Coons, 1954), and electron microscopical studies (Rake et al., 1948) that varicella and herpes zoster are produced by the same virus, Herpesvirus varicellae (varicella-zoster virus). According to Garland (1943) and others, herpes zoster, which occurs almost exclusively in adults, represents the reactivation of varicella-zoster virus which has remained latent in the neurones of the posterior root ganglia often for many years after a previous typical primary varicella infection. Alternatively, zoster may represent the clinical manifestations of an exogenous reinfection in a partially immune host.

This case of herpes zoster ophthalmicus in a child of 18 months is of special interest because of the history of varicella in the mother during the 35th week of pregnancy.

\section{Case Report}

An 18-month-old male child was admitted on 17 August 1970 with a four-day history of anorexia, prodromal symptoms of a cold, and swelling of the left upper eyelid on which a rash developed two days before admission.

He was drowsy and miserable and had a temperature of $100 \cdot 2^{\circ} \mathrm{F}$ $\left(37.9^{\circ} \mathrm{C}\right)$. There was a left conjunctivitis with swelling of the left upper eyelid, and an erythematous maculopapular rash with some vesiculation involving the left frontal region up to the mid-line, and the left side of the nose, corresponding to the area innervated by the ophthalmic branch of the fifth cranial nerve. The cornea was not involved. Two days later scattered erythematous maculopapular lesions developed on the left side of the face (see fig.) and over limited parts of the body, especially on the right side of the chest and in the left

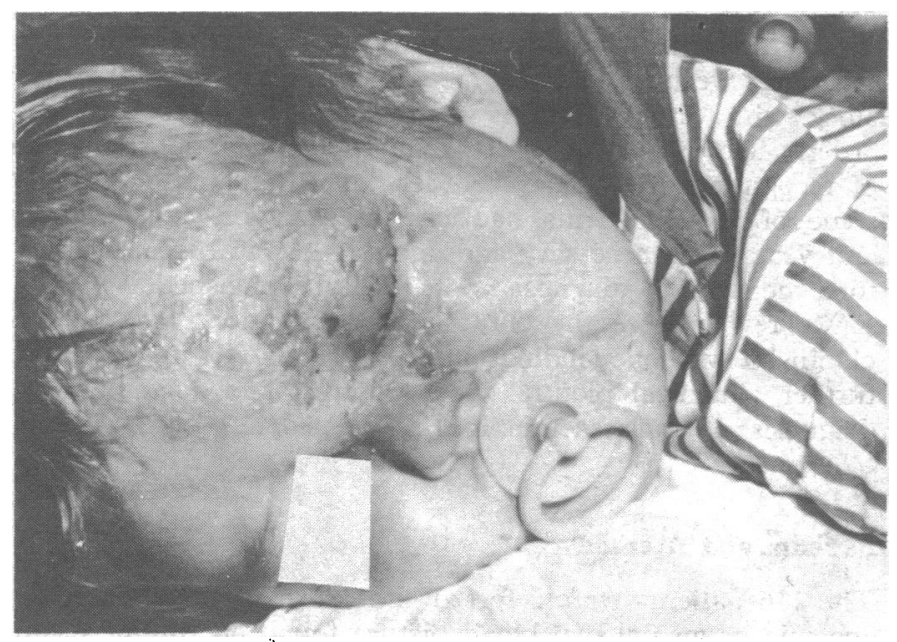

Facial appearance two days after admission.

University College Hospital, London WC1E 6AU

I. K. LEWKONIA, F.R.c.S., D.o., Senior Registrar, Ophthalmic Department A. A. JACKSON, M.B., M.R.C.P., Lately Paediatric House Physician lumbar region. The next day the temperature reached $104^{\circ} \mathrm{F}\left(40^{\circ} \mathrm{C}\right)$, and a left keratouveitis was evident.

The pregnancy had been uneventful until the mother developed varicella on 25 December 1968, five and a half weeks before term. The child was born by normal delivery at term.

At the age of 6 months the child was in close contact with his 7-year-old brother who developed varicella, but no skin lesions became apparent at that time.

The patient was treated with systemic ampicillin $125 \mathrm{mg}$ six-hourly, guttae atropine $0.5 \%$ twice daily and guttae Predsol-N hourly to the left eye, and Neo-Cortef cream to the affected eyelids. Eleven days after admission, when he was discharged, all the skin vesicles had disappeared, the cornea was clear, and there was no remaining evidence of anterior uveitis. Local treatment with guttae atropine $0.5 \%$ and guttae Predsol-N was continued until October 1970, by which time all the skin lesions had healed. A keloid which developed on the left side of the nose responded to fluocinolone cream.

Slit-lamp microscopy became possible in February 1971 and showed faint central corneal nebulae, and old keratic precipitates on the posterior corneal surface-a sequel to the previous anterior uveitis. In October a leash of fine mid-stromal vessels was seen advancing centrally from the temporal margin of the cornea, but it receded after treatment with guttae Predsol, one drop twice weekly. In February 1972 a mild left anterior uveitis recurred and was treated with guttae atropine $1 \%$ daily and guttae Predsol twice daily. The child continues to attend the outpatient department.

Virological Investigation.-Because infection with Herpesvirus hominis (herpes simplex) may produce vesicular lesions having a distribution similar to that of herpes zoster, laboratory confirmation of the diagnosis of zoster in a very young child is imperative. Varicellazoster virus was isolated from the vesicle swab'at the Virus Reference Laboratory, Colindale, after inoculation of human thyroid tissue (Meurisse, 1969). The virus was identified by the typical cytopathogenic changes produced. No serological studies were undertaken. Two children nursed in the same ward as the patient developed typical varicella within 12 days of his discharge from hospital.

Other Investigations. - Haemoglobin, $11.2 \mathrm{~g} / 100 \mathrm{ml}$; white blood count, $7,900 / \mathrm{mm}^{3}$ (neutrophils $35 \%$, lymphocytes $59 \%$, monocytes $4 \%$, eosinophils $2 \%$ ); urine, no abnormality detected.

\section{Comment}

In this case the development of herpes zoster ophthalmicus as a clinical manifestation of a primary infection with varicellazoster virus acquired from an unknown source cannot be refuted. However, taking account of the currently accepted views concerning the pathogenesis of herpes zoster, the child's previous exposure to varicella in utero and at the age of 6 months cannot be ignored.

If primary subclinical infection occurred on either of these occasions, reactivation of latent varicella-zoster virus or exogenous reinfection in a partially immune host is a more likely explanation for the development of herpes zoster ophthalmicus at this young age.

We are grateful to Mr. D. P. Greaves and Professor L. B. Strang for allowing us to report this case in their care. We acknowledge the helpful advice given by Dr. A. Cohen in the preparation of this paper. The virological investigations were kindly undertaken by Dr. E. Valerie Meurisse, Virus Reference Laboratory, Colindale, London N.W.9.

\section{References}

Garland, J. (1943). New England fournal of Medicine, 228, 336.

Meurisse, E. V. (1969). Fournal of Medical Microbiology, 2, 317.

Rake, G., Blank, H., Coriell, L. L., Nagler, F. P. O., and Scott, T. F. M. (1948). Fournal of Bacteriology, 56, 293.

Weller, T. H. (1958). The Harvey Lectures, 52, 228.

Weller, T. H., and Coons, A. H. (1954). Proceedings of the Society for Experimental Biology and Medicine, 86, 789 . 